\title{
A GASE OF THE KLIPPEL-FEIL SYNDROME
}

\author{
BY \\ JOHN THOMSON, M.B., Ch.B., D.P.H. \\ (Late Assistant Medical Officer of Health, Fife County Council.)
}

\section{Clinical record}

This child, a girl, born 4.11.27, was seen at school medical inspection in December, 1934. Birth had been normal and she was breast fed for six months. She cut the first tooth at ten months, spoke the first single words at eighteen months, first walked at twenty-one months and first walked without falling at two years and seven months. Soon after birth it was observed that:-1. The head was tilted to the left side. 2. Strabismus was present. 3. The mouth was drawn up and to the right.

The child was seen as an out-patient at the Royal Hospital for Sick Children, Edinburgh, on three occasions, $2.10 .29 ; 27.6 .31 ; 7.6 .33$. She was an in-patient in the hospital from 14 to 25.7.31. It was observed in hospital that:-1. The neck was very short and stiff. 2. The head was thrust forward and to the left. 3. Left sterno-mastoid and left trapezius were shortened, grossly thickened and hard almost to the extent of feeling ossified. 4. There appeared to be some wasting of the scapular muscles. 5. Bony asymmetry of the face was present, the left side being smaller. 6 . There was a cervico-dorsal scoliosis. 7. The child was weak, small for her age, slow in grasping things with her hands. 8. There was some weakness of the left arm and leg. 9. There was some paresis of the left side of the face, of the external rectus, and the left levator palpebrae. Subsequently, this paresis cleared up. 10. There was also slight left sided enlargement of the heart with a systolic murmur of maximum intensity a quarter of an inch outside the left sternal border, at the level of the nipple. This also cleared up.

An x-ray photograph taken on 17.7.31 shows (see fig. 1):-1. The seventh cervical vertebra has the tip of its spine fused with those of the

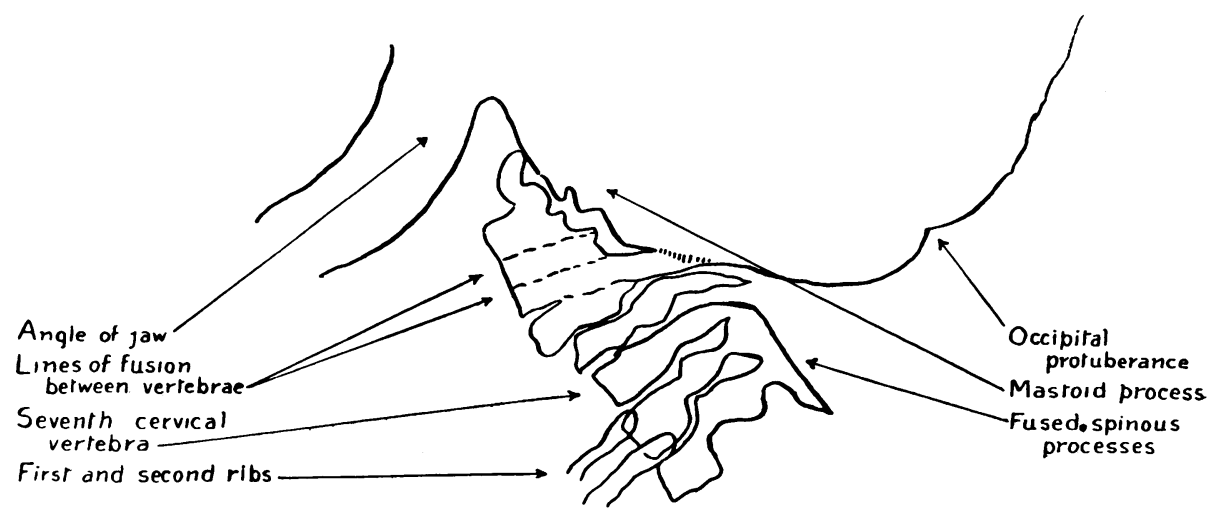

FIG. 1.-Drawing from skiagram taken on 17.7.31. 
first and second thoracic vertebrae. 2. The sixth cervical vertebra is flattened from above downwards and has its body fused to the fifth cervical vertebra above. 3. The bony elements representing the fifth, fourth, third and second cervical vertebrae are displaced forwards by a quarter of an inch, and are fused together. Their common fused spine is in contact with the base of the skull, one inch in front of the occipital protuberance. 4. The odontoid process of the second cervical vertebra is fused to the posterior aspect of the anterior transverse arch of the first cervical vertebra.

\section{Condition at beginning of treatment}

On March 18, 1935, remedial exercises, with posture training and massage were begun. Hyperextension of the spine twice a day for half an hour with the hands clasped behind the head was also practised at home. The appearance of the child at the beginning of her treatment is shown in fig. $2 \mathrm{~A}$.

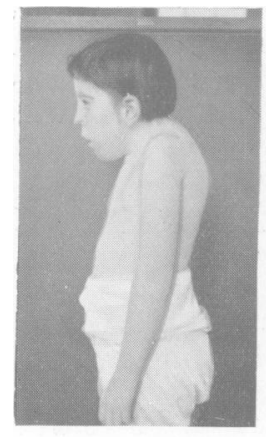

A

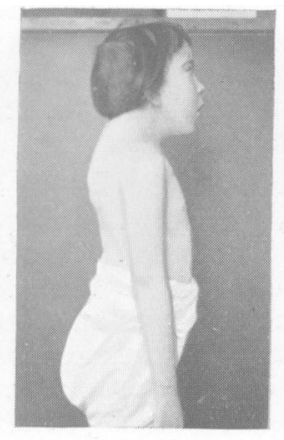

B

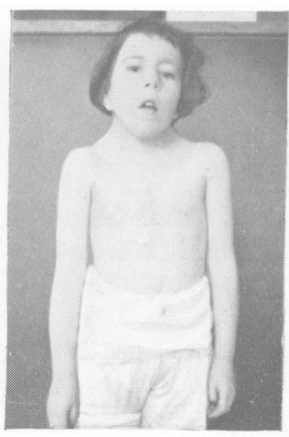

C

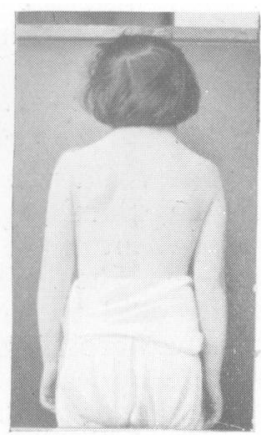

D

FIG. 2.

The following typical signs are seen:-1. Short neck with low hair line and nuchal depression. 2. Kyphosis. 3. Position of head with upward look of the eyes. 4. High scapulae with some winging obscuring the curve of the spine. 5. Open mouth. In addition therc was present, 6. Facial asymmetry and torticollis. 7. Contracture of all neck muscles, especially sterno-mastoids and trapezius. 8. Webbed neck. 9. Only slight head movements. 10. Elevation of left shoulder. 11. Mouth breathing.

It was also observed that whilst bimanual synkinesia was not present as it is classically described, complete dissociation of the movements of the hands had not been attained; e.g. when the child buttoned up her coat with the right hand alone, the left hand and fingers especially, were in a state of constant motion, as though they might be also handling buttons. Educationally, the child was backward. She attended at the orthopaedic clinic regularly as an out-patient, three times a week, and despite her educational backwardness proved to be an apt pupil.

Her posture and general carriage improved tremendously as will be seen from fig. 2B taken in September, 1936. The range of movement in the spinal column as a whole was greatly increased, while the strength and tone of the spinal muscles was vastly improved. Head movements also increased slightly. Educationally too, the child has improved. The other signs of the condition are naturally unaffected by the treatment. 


\section{Discussion}

This condition, as originally described by Klippel and Feil ${ }^{1,2,3}$, was stated to consist of (1) a numerical variation of the vertebrae; (2) more or less fusion between the bony elements of the cervical vertebrae; (3) accompanied sometimes by spina bifida or other congenital abnormalities.

So far some seventy to eighty cases have been reported in medical literature. Although the first detailed description, including post-mortem findings was given by Klippel and Feil, the first case recorded appears to be that of J. Jackson Clarke ${ }^{4}$. He instances ' a boy aged $4 \mathrm{yr}$. who from birth had had the head fixed so that the chin was close to the sternum and there was no movement in the cervical spine. The personal appearance recalled cases of anencephaly.' At about the same time as Klippel and Feil published their detailed findings of the condition, Meisenbach ${ }^{5}$ reported a case of absence of the cervical spine. This nomenclature however, though it is used by many subsequent writers, is inaccurate, since in no case is the cervical spine completely absent. A further monograph on the subject was published by Feil in $1919^{6}$, and since then a number of cases have been recorded. These are for the most part in the French literature, but cases are reported from Italy, Germany, Roumania (Vaselescu and Niculiscu ${ }^{7}$ ), Russia $\left(\mathrm{Kroll}^{8}\right.$, Yankelevich ${ }^{9}$ ), Scandinavia (Elowson ${ }^{10}$ ), and a number are reported in the English literature by American and British writers (Baumann ${ }^{11}$, Greenberg ${ }^{12}$, Willard and Nicholson ${ }^{13}$, Mitchell ${ }^{14}$, Clarke $^{4}$, Foggie $\left.^{15}\right)$.

Etiology.- The cause of this condition has not yet been defined. All that can be said is that the condition is essentially an intra-uterine one. It is natural to look for a primary defect in the osseous system, but the frequent presence of mental defect as well as certain nervous phenomena, of which bimanual synkinesia ${ }^{11}, 13,14,15$, is the most striking, show that the nervous system is not free from suspicion. The cause of this disturbance of the mesoderm or of the embryonal skeletal axis is open to speculation. Both disease of, and a low vitality of, the germ plasm have been offered as an explanation.

The condition does not appear to be a hereditary one, although Foggie ${ }^{15}$ calls attention to the fact that Feil reports a case of the condition occurring in father and son; Kallius, of its occurring in father and daughter; Sicard and Lermoyez, of it occurring in a mother and three of her children.

Symptoms and signs. - Of these the most prominent is the short neck. So much is this so, that in Germany the condition is known as 'Kurzhals.' In France it goes by the name of ' les hommes sans cou'; and in this country it has been referred to as 'brevi collis.' As a result, a low hair line is seen at the back of the neck, and there is a distinct depression to be seen at the nape of the neck. It is referred to as the nuchal depression. The shortness of the neck is exaggerated by a kyphosis which is present in the dorsal region. The scapulae tend to be higher than usual and this also is exaggerated by the kyphosis present. The head is thrown forward and it appears as if the bony skeleton were not able to support it, for in extreme cases the chin may actually rest on the thorax. The head movements are of necessity limited. There is a degree of muscle spasm present in the cervical muscles. It is explained as being due to the muscles requiring to 
take the place of the osseous system in supporting the head (Baumann ${ }^{11}$ ). There is a flattening out of the trapezius muscles giving rise to a broad appearance of the neck, and this is referred to by some writers as webbed neck. Torticollis is frequently present, and although facial asymmetry is not always obvious, its presence is not uncommon. Disturbance of the breathing may be present in the form of an obstruction, thus giving rise to the typical facies seen in adenoids. There may also be difficulty in swallowing. Spina bifida may be present, also bimanual synkinesia, deafmutism, disturbance of ocular movements, and various other congenital defects in different parts of the body, e.g. direct communication between the two ventricles of the heart. Some of these other congenital defects may be incompatible with life, and indeed of Mitchell's ${ }^{14}$ six cases, two so affected died, one aged five weeks, and one aged six weeks.

Differential diagnosis.-The condition must be differentiated from Sprengel's shoulder, ordinary wryneck and tuberculosis of the vertebrae. There should be little difficulty in differentiating from Sprengel's shoulder, but it is confessed that the condition has been treated surgically as an ordinary wryneck. When this was done, no benefit accrued to the patient. The differentiation from tuberculosis of the vertebrae may not be so easy. The presence however of:-(1) Shortness of the neck-so short that the thorax reaches almost to the head-referred to by Klippel and Feil as the ' cervical thorax'; (2) the broadness of the neck; (3) the low hair line; (4) absence of pain; and (5) muscle spasm should differentiate the two conditions. Mention should be made here however that Yankelevich ${ }^{9}$, has reported a case in which tuberculosis of the vertebrae co-existed.

Treatment. - In Jackson Clarke's case it is stated that ' operative treatment followed by massage gave to the boy a short neck with all the natural movements.' There is, however, no indication of the nature of the operative treatment carried out. Baumann ${ }^{11}$ states, ' The deformity is stationary and not affected by treatment, it is disguised only with difficulty, and does not become less conspicuous as the patient develops.' Greenberg ${ }^{12}$ says, ' therapeutic expectations are absolutely nil.' Other writers do not touch upon the question of treatment at all. It would appear, however, that despite the somewhat pessimistic pronouncements of some writers concerning the treatment of the condition, the present case tends to show that some improvement may be looked for: even when there is a degree of mental defect present, always provided that it is not such as to cause failure to secure that co-operation which is so necessary between the patient and the masseuse in carrying out this treatment. Whether the result of such treatment will 'be of permanent benefit or not remains to be seen. This patient is still under observation, being seen about once a week, during the school term.

Thanks are due to Prof. Charles McNeil for permission to peruse and make use of the notes of the case, and also the x-ray film, made when the child was in the Royal Hospital for Sick Children, Edinburgh. 


\section{REFERENGES.}

1. Klippel, M., \& Feil, A., Bull. et mem. Soc. anat. de Paris, Paris, 1912, LXXXVII, 185.

2. Idem, N. iconog. de la Salpêtrière, Paris, Paris, 1912, XXV, 223.

3. Idem, Bull. et mem. Soc. d'anthrop de Paris, Paris, 1912, III, 101.

4. Clarke, J. J., Lancet, London, 1906, ii, 1350.

5. Meisenbach, R. O., Am. J. Orthop. Surgery, Philadelphia, 1912, X, 647.

6. Feil, A., L'absence et la diminution des vertèbres cervicales, Paris, 1919.

7. Vasilescu, A., \& Niculescu, S., Bull. et mem. Soc. méd. d. hop. de Bucarest, Bucarest, 1923, V, 13.

8. Kroll, M., Mosk. Med. J., Moscow, 1928, VIII, 65.

9. Yankelevich, T. Y., Sovit. nevropat., psikhiat. i. psikhogig., Moscow, 1933, II, 155.

10. Elowson, S., Acta. chir. Scandinav., Stockholm, 1930, LXVII, 326.

11. Baumann, G. I., J. Am. Med. Ass., Chicago, 1932, XCVIII, 129.

12. Greenberg, L., Jour. Bone and Joint Surgery, Boston, 1933, XV, 444.

13. Willard, DeF. P., \& Nicholson, J. T., Ann. Surg., Philadelphia, 1934, XCIX, 561.

14. Mitchell, H. S., Arch. Dis. Childh., London, 1934, IX, 213.

15. Foggie, W. E., Edin. Med. J., Edinburgh, 1935, XLII, 421. 